\title{
MPPT of Solar PV Panels using Chaos PSO Algorithm under Varying Atmospheric Conditions
}

\author{
Duy C. Huynh \\ HoChiMinh City University of Technology \\ HoChiMinh City, Vietnam
}

\begin{abstract}
This paper proposes a novel application of a chaos particle swarm optimization (PSO) algorithm for tracking a maximum power point (MPP) of a solar photovoltaic (PV) panel under varying atmospheric conditions. Solar PV cells have a nonlinear V-I characteristic with a distinct MPP which depends on environmental factors such as temperature and irradiation. In order to continuously harvest maximum power from the solar PV panel, it always has to be operated at its MPP. The proposed chaos PSO algorithm is one of the standard PSO algorithm variants. A chaos PSO algorithm with a logistic map has been used for initializing random values of MPPs, as well as the inertia weight in the velocity update equation of the standard PSO algorithm. This creates the best balance for the inertia weight during the evolution process of the standard PSO algorithm which results in the best convergence capability and search performance. Additionally, the algorithm has also been improved with regards to the diversity in the solution space through two independent chaotic random sequences. The obtained simulation results are compared with MPPs achieved using other algorithms such as the standard PSO, and Perturbation and Observation (P\&O) algorithms. The results show that the chaos PSO algorithm is better than the standard PSO and P\&O algorithms for tracking MPPs of solar PV panels.
\end{abstract}

Keywords - Solar photovoltaic panels, Maximum power point tracking, and Particle swarm optimization algorithm.

\section{INTRODUCTION}

Solar energy is popularly used to provide heat, light and electricity. One of the important technologies of solar energy is photovoltaic (PV) which converts irradiation directly to electricity by the photovoltaic effect [1]. However, the solar PV generation panels have two main problems. Firstly, the conversion efficiency of solar PV cells is very low (9\% to $17 \%$ ), especially under low irradiation conditions. Secondly, the amount of electric power which is generated by solar PV panels changes continuously with various weather conditions. In addition, the V-I characteristic of the solar cell is non-linear and varies with irradiation and temperature [2]. But in general, there is always a unique point on the V-I or V-P curve which is called the Maximum Power Point (MPP). This means that the solar PV system will operate with maximum efficiency and produce a maximum output power. The MPP is not known on the V-I or V-P curve, but it can be located by search algorithms such as the Perturbation and Observation (P\&O) algorithm [3]-[4], the Incremental Conductance (IC) algorithm [5]-[6], the Constant Voltage (CV) algorithm [7]-[8], the Artificial Neural Network (ANN) algorithm [9], the Fuzzy Logic (FL) algorithm [10]-[11], the Particle Swarm
Optimization (PSO) algorithm [12]-[13]. These existing algorithms have several advantages and disadvantages concerned with simplicity, convergence speed, extra hardware and cost. This paper proposes a chaos Particle Swarm Optimization (PSO) algorithm for searching a MPP on the V-I characteristic of the solar PV panel. The simulation results using the chaos PSO algorithm are compared to using the standard PSO and P\&O algorithms and confirm the effectiveness and benefit of the proposed algorithm. The remainder of this paper is organized as follows. The mathematical model of solar PV panels is described in Section 2. A novel proposal using the chaos PSO algorithm is presented in Section 3. The simulation results then follow to confirm the validity of the proposed algorithm in Section 4. Finally, the advantages of the new proposal are summarized through comparison with several related existing approaches such as the standard PSO and P\&O algorithms.

\section{Solar Photovoltaic SYSTEMS}

The mathematical model of a solar PV cell is described by the following set of equations:

$$
\begin{aligned}
& \mathrm{I}=\mathrm{I}_{\mathrm{sc}}-\mathrm{I}_{0}\left(\mathrm{e}^{\frac{\mathrm{qV}}{\mathrm{kT}}}-1\right) \\
& \mathrm{V}_{\mathrm{oc}}=\frac{\mathrm{kT}}{\mathrm{q}} \ln \left(\frac{\mathrm{I}_{\mathrm{sc}}}{\mathrm{I}_{0}}+1\right) \\
& \mathrm{P}=\mathrm{V} \times \mathrm{I}=\mathrm{VI}_{\mathrm{sc}}-\mathrm{VI}_{0}\left(\mathrm{e}^{\frac{\mathrm{qV}}{\mathrm{kT}}}-1\right)
\end{aligned}
$$

where

$I$ : the current of the solar PV cell (A)

$V$ : the voltage of the solar PV cell (V)

$P$ : the power of the solar PV cell (W)

$I_{s c}$ : the short-circuit current of the solar PV cell (A)

$V_{o c}$ : the open-circuit voltage of the solar PV cell (V)

$I_{0}$ : the reverse saturation current (A)

$q$ : the electron charge $(\mathrm{C}), q=1.602 \times 10-19(\mathrm{C})$

$k$ : Boltzmann's constant, $k=1.381 \times 10-23(\mathrm{~J} / \mathrm{K})$

$T$ : the panel temperature $(\mathrm{K})$

It is realized that the solar PV panels are very sensitive to shading. Therefore, a more accurate equivalent circuit for a solar PV cell is presented to consider the impact of shading as well as account for the losses due to the module's internal series resistance, contacts and interconnections between cells 
and modules. Then, the V-I characteristic of a solar PV cell is written as follows:

$$
I=I_{s c}-I_{0}\left(e^{\frac{q\left(V+R_{s}\right)}{k T}}-1\right)-\left(\frac{V+I_{s}}{R_{p}}\right)
$$

where

$R_{s}$ and $R_{p}$ : the resistances used to consider the impact of shading and losses.

Although, the manufactures try to minimize the effect of both resistances to improve their products, the ideal scenario is not possible.

Two important points of the V-I characteristic that must be pointed out are the open-circuit voltage, $V_{o c}$ and the shortcircuit current, $I_{s c}$. The power generated is zero at both points. The $V_{o c}$ is determined when the output current, $I$ of the cell is zero $(I=0)$ whereas the $I_{s c}$ is determined when the output voltage, $V$ of the cell is zero $(V=0)$. The maximum power is generated by the solar PV cell at a point of the V-I characteristic where the product $(V \times I)$ is maximum. This point is known as the MPP and is unique.

It is obvious that two important factors which have to be taken into account in the electricity generation of a solar PV panel are the irradiation and temperature. These factors strongly affect the characteristics of solar PV panels. As a result, the MPP varies during the day. If the operating point is not close to the MPP, significant power losses occur. Thus, it is essential to track the MPP in all conditions to ensure that the maximum available power is obtained from the solar PV panel. This problem is entrusted to the maximum power point tracking (MPPT) algorithms through searching and determining MPPs in various conditions. This paper proposes the chaos PSO algorithm for searching MPPs which is presented in more detail in the next part.

\section{Chaos Particle SWARM OPTIMIZATION Algorithm BASED MAXIMUM POWER POINT TRACKING}

The standard particle swarm optimization approach is reviewed in the section A followed by a description of the chaos PSO algorithm.

\section{A. Particle Swarm Optimization Algorithm}

The particle swarm optimization (PSO) algorithm is a population-based stochastic optimization method which was developed by Eberhart and Kennedy in 1995 [14]. The algorithm was inspired by the social behaviors of bird flocks, colonies of insects, schools of fishes and herds of animals. The algorithm starts by initializing a population of random solutions called particles and searches for optima by updating generations through the following velocity and position update equations.

The velocity update equation:

$$
\begin{aligned}
\boldsymbol{v}_{i}(\mathrm{k}+1) & =\mathrm{w} \boldsymbol{v}_{i}(\mathrm{k})+\mathrm{c}_{1} \mathrm{r}_{1}\left(\boldsymbol{p b e s t}_{i}(\mathrm{k})-\boldsymbol{x}_{i}(\mathrm{k})\right)+ \\
& +\mathrm{c}_{2} \mathrm{r}_{2}\left(\boldsymbol{g} \boldsymbol{\operatorname { c e s t }}(\mathrm{k})-\boldsymbol{x}_{i}(\mathrm{k})\right)
\end{aligned}
$$

The position update equation:

$$
\boldsymbol{x}_{i}(\mathrm{k}+1)=\boldsymbol{x}_{i}(\mathrm{k})+\boldsymbol{v}_{i}(\mathrm{k}+1)
$$

where

$v_{i}(k)$ : the $k$ th current velocity of the $i$ th particle. $\boldsymbol{x}_{i}(k)$ : the $k$ th current position of the $i$ th particle.

$k$ : the $k$ th current iteration of the algorithm, $1 \leq k \leq n$. $n$ : the maximum iteration number.

$i$ : the $i$ th particle of the swarm, $1 \leq i \leq N$.

$N$ : the particle number of the swarm.

Usually, $\boldsymbol{v}_{i}$ is clamped in the range $\left[-v_{\max }, v_{\max }\right]$ to reduce the likelihood that a particle might leave the search space. In case of this, if the search space is defined by the bounds $\left[-x_{\max }, x_{\max }\right]$ then the $v_{\max }$ value will be typically set so that $v_{\max }=m x_{\max }$, where $0.1 \leq m \leq 1.0$ [15].

pbest $_{i}(k)$ : the best position found by the $i$ th particle (personal best).

$\operatorname{gbest}(k)$ : the best position found by a swarm (global best, best of the personal bests).

$c_{1}$ and $c_{2}$ : the acceleration coefficients called cognitive and social parameters respectively; the $c_{2}$ regulates the step size in the direction of the global best particle and the $c_{1}$ regulates the step size in the direction of the personal best position of that particle; $c_{1}$ and $c_{2} \in[0,2]$. With large cognitive and small social parameters at the beginning, particles are allowed to move around a wider search space instead of moving towards a population best. Additionally, with small cognitive and large social parameters, particles are allowed to converge to the global optima in the latter part of optimization [16].

$r_{1}$ and $r_{2}$ : two independent random sequences which are used to effect the stochastic nature of the algorithm, $r_{l}$ and $r_{2} \in \mathrm{U}(0,1)$.

$w$ : is called an inertia weight [17]. This value was set to 1 in the original PSO [14]. Shi and Eberhart [17] investigated the effect of $w$ values in the range $[0,1.4]$, as well as in a linear time-varying domain. Their results indicated that choosing $w$ $\in[0.9,1.2]$ results in a faster convergence. A larger inertia weight facilitates a global exploration and a smaller inertia weight tends to facilitate a local exploration [18]. Thus the balance of the inertia weight $w$ during the evolution process of the PSO is necessary. This improves the convergence capability and search performance of the algorithm.

In this MPPT application, the fitness function, $\mathrm{f}(\mathrm{V}, \mathrm{I})$ depends on $(\mathrm{V}, \mathrm{I})$ and obtains its maximum at $\operatorname{MPPs}\left(V_{m p p}\right.$, $\left.I_{m p p}\right)$, where

$\mathrm{f}(\mathrm{V}, \mathrm{I})=\mathrm{VI}_{\mathrm{sc}}-\mathrm{VI}_{0}\left(\mathrm{e}^{\frac{\mathrm{q}\left(\mathrm{V}+\mathrm{IR}_{\mathrm{s}}\right)}{\mathrm{kT}}}-1\right)-\mathrm{V}\left(\frac{\mathrm{V}+\mathrm{IR}_{\mathrm{s}}}{\mathrm{R}_{\mathrm{p}}}\right)$

Using the standard PSO algorithm, the $i$ th particle is represented as $\left\{\boldsymbol{V}_{\boldsymbol{m p p} \boldsymbol{i}}, \boldsymbol{I}_{\boldsymbol{m p p} \boldsymbol{i}}\right\}$. The best position found for the $i$ th particle is represented as $\left\{\right.$ pbest $_{\text {Vmppi }}$, pbest $\left.\boldsymbol{p}_{\text {Impp } i}\right\}$. The rate of the position change, which is the velocity for the $i$ th particle, is represented as $\left\{\boldsymbol{v}_{V m p p i}, \boldsymbol{v}_{\text {Imp } i}\right\}$. The best position found by the swarm is represented as $\left\{\right.$ gbest $_{V m p p}$, gbest $\left._{\text {Impp }}\right\}$. The fitness function (7) plays the important role in searching the best position for the $i$ th particle and the best position of the swarm. The position and velocity of the $i$ th particle are updated using (5)-(6). In this application, the initial positions and velocities of the $i$ th particle are random sequences; the inertia weight $w$ is set to 0.9 ; the cognitive and social parameters are set to 2 ; 
the two independent random sequences $r_{1}$ and $r_{2}$ are uniformly distributed in $\mathrm{U}(0,1)$. It is obvious that the standard PSO algorithm is one of the simplest and most efficient global optimization algorithms, especially in solving discontinuous, multimodal and non-convex problems. However, for local optima problems, the particles sometimes become trapped in undesired states during the evolution process which leads to the loss of the exploration abilities. Because of this disadvantage, premature convergence can happen in the standard PSO algorithm which affects the performance of the evolution process. This is one of the major drawbacks of the standard PSO algorithm. In order to improve the performance of the standard PSO algorithm, the variant of the standard PSO algorithm, known as the chaos PSO algorithm is presented in the next section.

\section{B. Chaos Particle Swarm Optimization Algorithm}

A chaos PSO algorithm is a combination algorithm between the standard PSO algorithm and a chaotic map which is proposed in the initialization and evolution process of the standard PSO algorithm [18-23]. Chaos is a common phenomenon in non-linear systems which includes infinite unstable period motions. It is a stochastic process in a deterministic non-linear system. A chaotic map is a discretetime dynamical system [18] as follows,

$$
x_{k}=f\left(x_{k-1}\right)
$$

where $x_{(k-1)} \in(0,1), k=1,2, \ldots$

The sequences are generated by using one of the chaotic maps known as chaotic sequences. These sequences have the characteristics of the chaotic map such as randomness, ergodicity and regularity so that no state is repeated. The chaotic sequences are considered as sources of random sequences which are applied for randomness-based parameters in the chaos PSO algorithm. In this case, the chaotic sequences are an appropriate tool to support the standard PSO algorithm so that it avoids getting stuck in a local optimum during the search process and overcomes the premature convergence phenomenon present in the standard PSO algorithm. There are many chaotic maps which have been introduced which can be used to improve the standard PSO algorithm [18]. Amongst them, the logistic map is one of the simplest and easiest maps to employ in the chaos PSO algorithm for tracking MPPs of a solar PV panel under varying atmospheric conditions.

A logistic map is given as follows:

$$
X_{k}=a X_{(k-1)}\left(1-X_{(k-1)}\right), k=1,2, \ldots
$$

where $X_{k}$ : the $k$ th chaotic number under the initial conditions as follows: $X_{0}$ is a random number in the interval of $(0,1)$ and $X_{0} \notin\{0.0,0.25,0.5,0.75,1.0\}$.

$a$ : the control parameter and usually set to 4 in the experiments [18].

The logistic map is used in the parameter estimation application for initializing the positions $\left\{V_{m p p i}, I_{m p p i}\right\}$ and velocities $\left\{v_{V m p p i}, v_{\text {Impp } i}\right\}$ of the ith particle, as well as a random sequence for the inertia weight $\mathrm{w}$ in the velocity update equation of the chaos PSO algorithm. This creates the best balance for the inertia weight during the evolution process of the chaos PSO algorithm between the local and global search processes which results in the best convergence capability and search performance. The chaotic inertia weight is:

$$
w_{k}=a w_{(k-1)}\left(1-w_{(k-1)}\right)
$$

where

$w_{k}$ : the $k$ th chaotic inertia weight. The $w_{k} \in(0,1)$ is under the initial conditions as follows: the $w_{0}$ is a random number in the interval of $(0,1)$ and $w_{0} \notin\{0.0,0.25,0.5,0.75,1.0\}$.

Additionally, the logistic map is also used to improve the diversity in the solution space through the two independent chaotic random sequences $\mathrm{r}^{1}$ and $\mathrm{r}^{2}$ in the velocity update equation. The two independent chaotic random sequences are:

$$
\begin{aligned}
& r_{k}^{1}=\operatorname{ar}_{(k-1)}^{1}\left(1-r_{(k-1)}^{1}\right) \\
& r_{k}^{2}=\operatorname{ar}_{(k-1)}^{2}\left(1-r_{(k-1)}^{2}\right)
\end{aligned}
$$

where $r_{k}^{l}$ and $r_{k}^{2}$ : the two $k$ th independent chaotic random sequences. The $r_{k}{ }_{k}$ and $r_{k}^{2} \in(0,1)$ are under the initial conditions as follows: the $\mathrm{r}_{0}^{1}$ and $\mathrm{r}_{0}^{2}$ are random numbers in the interval of $(0,1)$ and $r_{0}^{1}$ and $r_{0}^{2} \notin\{0.0,0.25,0.5,0.75$, $1.0\}$. Thus the velocity update equation of the standard PSO algorithm is re-written as follows:

$$
\begin{aligned}
\boldsymbol{v}_{i}(\mathrm{k}+1) & =\mathrm{w}_{\mathrm{k}} \boldsymbol{v}_{i}(\mathrm{k})+\mathrm{c}_{1} \mathrm{r}_{\mathrm{k}}^{1}\left(\boldsymbol{p b}_{\boldsymbol{e}} \boldsymbol{e s} \boldsymbol{t}_{i}(\mathrm{k})-\boldsymbol{x}_{i}(\mathrm{k})\right)+ \\
& +\mathrm{c}_{2} \mathrm{r}_{\mathrm{k}}^{2}\left(\boldsymbol{g} \boldsymbol{b} \boldsymbol{e s t}(\mathrm{k})-\boldsymbol{x}_{i}(\mathrm{k})\right)
\end{aligned}
$$

where $w_{k}, r_{k}^{1}$ and $r_{k}^{2}$ : the logistic maps.

\section{Simulation RESUltS}

Simulations are performed using MATLAB/SIMULINK software for tracking MPPs of the solar PV panel, BP-MSX120. The specifications and parameters of BP-MSX-120 are listed in Table I [24]. The standard PSO and chaos PSO algorithms are applied for tracking MPPs in which the particle number of a generation is set to 50 and the maximum iteration number is set to 200 .

Fig. 1 are the V-I and V-P characteristics of the solar PV panel, BP-MSX-120 for different irradiation values, $G=(1000$ to 5000$) \mathrm{W} / \mathrm{m}^{2}$ at the temperature, $T^{0} C=25^{\circ} \mathrm{C}$ and Fig. 2 is for different temperature values, $T^{0} C=(25 \text { to } 100)^{0} \mathrm{C}$ at the irradiation, $G=1000 \mathrm{~W} / \mathrm{m}^{2}$. The solar PV panel provides a maximum output power at a MPP with $V_{M P P}$ and $I_{M P P}$. The MPP is defined at standard test condition (STC) of the irradiation, $1000 \mathrm{~W} / \mathrm{m}^{2}$ and module temperature, $25^{\circ} \mathrm{C}$ but this condition does not exist in the most of the time. Thus, the output power of the solar PV panel will be less than the maximum output power. Figs. 1-2 show that the output voltage and current are affected by the variations in the irradiation and temperature. However, under any atmospheric condition, there is a unique maximum point on the V-I or V-P curve, at which the solar PV panel operates with maximum efficiency and produces maximum output power. Table II shows that the tracking efficiency of MPPs is low when using the standard PSO algorithm due to its drawbacks whereas it is better when using the chaos PSO and P\&O algorithms, Fig. 5. Table III shows the tracking ability of MPPs of the standard PSO, chaos PSO and P\&O algorithms. The efficiency 
produced by the proposed algorithm is always higher than 95\% and higher than the efficiencies achieved when using the standard PSO and P\&O algorithms. This shows that the chaos PSO algorithm is better than the standard PSO and P\&O algorithms for tracking MPPs of solar PV panels. Figs. 3-4 are the best fitness of the standard PSO and chaos PSO algorithms versus the iteration step number that show the convergence capability of each algorithm. It can be realized easily that there are several differences between the standard PSO and chaos PSO algorithms such as initializing of the particles' positions and velocities using the chaotic map, the chaotic inertia weight and two chaotic independent random sequences in the velocity update equation. These enhance the solution quality of the algorithm. The chaos PSO algorithm is better than the standard PSO algorithm in terms of both the convergence speed and value. The convergence value of the standard PSO algorithm is 0.194 whereas that of the chaos PSO algorithm is $3.156 \times 10^{-7}$. The standard PSO algorithm converges at the 11th iteration step whereas the chaos PSO algorithm converges at the 9 th iteration step respectively.

TABLE I

SPECIFICATIONS AND PARAMETERS OF THE SOLAR PV PANEL, BP-MSX-120

\begin{tabular}{|l|l|}
\hline Maximum power, $P_{\max }$ & $120 \mathrm{~W}$ \\
\hline Voltage at $P_{\max }, V_{M P P}$ & $33.70 \mathrm{~V}$ \\
\hline Current at $P_{\max }, I_{M P P}$ & $3.56 \mathrm{~A}$ \\
\hline Short-circuit current, $I_{s c}$ & $3.87 \mathrm{~A}$ \\
\hline Open-circuit voltage, $V_{o c}$ & $42.10 \mathrm{~V}$ \\
\hline Panel series resistance, $R_{s}$ & $0.47 \Omega$ \\
\hline Panel parallel (shunt) resistance, $R_{p}$ & $1365 \Omega$ \\
\hline Standard test condition of irradiation, $G$ & $1000 \mathrm{~W} / \mathrm{m}^{2}$ \\
\hline Standard test condition of temperature, $T$ & $25^{\circ} \mathrm{C}$ \\
\hline
\end{tabular}

TABLE II

TRACKING EFFICIENCY OF THE MPPS OF THE SOLAR PV PANEL USING THE STANDARD PSO, CHAOS PSO AND P\&O ALGORITHMS

\begin{tabular}{|c|c|c|l|c|c|}
\hline $\begin{array}{c}\text { Case } \\
\text { No. }\end{array}$ & \multirow{G}{G}{$\left(\mathbf{W} / \mathbf{m}^{\mathbf{2}}\right)$} & \multirow{2}{*}{$\left.\mathbf{(}^{\mathbf{0}} \mathbf{C}\right)$} & \multicolumn{3}{|c|}{$\begin{array}{c}\text { Tracking efficiency of the } \\
\text { MPPs (\%) }\end{array}$} \\
\cline { 3 - 6 } & & & $\begin{array}{c}\text { Standard } \\
\text { PSO }\end{array}$ & $\begin{array}{c}\text { Chaos } \\
\text { PSO }\end{array}$ & P\&O \\
\hline 1 & 1000 & 25 & 88.75 & 99.66 & 94.78 \\
\hline 2 & 1000 & 50 & 89.27 & 99.75 & 97.57 \\
\hline 3 & 2000 & 25 & 79.28 & 98.70 & 90.72 \\
\hline 4 & 2000 & 50 & 79.85 & 99.02 & 92.23 \\
\hline 5 & 3000 & 30 & 94.75 & 97.23 & 91.77 \\
\hline 6 & 3000 & 40 & 98.03 & 98.27 & 91.90 \\
\hline 7 & 4000 & 30 & 83.12 & 99.20 & 88.93 \\
\hline 8 & 4000 & 40 & 88.70 & 98.67 & 92.77 \\
\hline 9 & 5000 & 35 & 83.83 & 98.82 & 95.64 \\
\hline 10 & 5000 & 45 & 92.41 & 99.90 & 95.71 \\
\hline
\end{tabular}
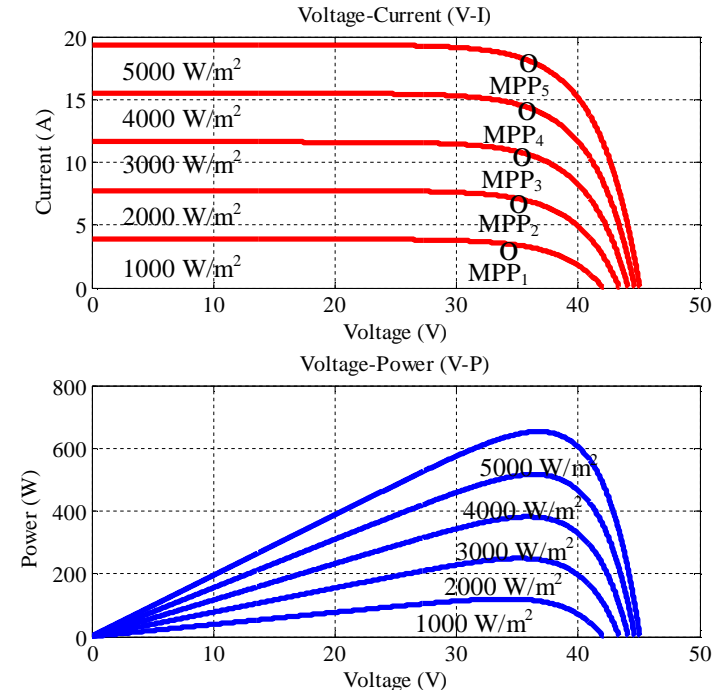

Fig. 1 V-I and V-P characteristics of the solar PV panel for different irradiation values, $\mathrm{G}=(1000$ to 5000$) \mathrm{W} / \mathrm{m}^{2}$ at the temperature, $\mathrm{T}^{0} \mathrm{C}=25^{0} \mathrm{C}$ Voltage-Current (V-I)
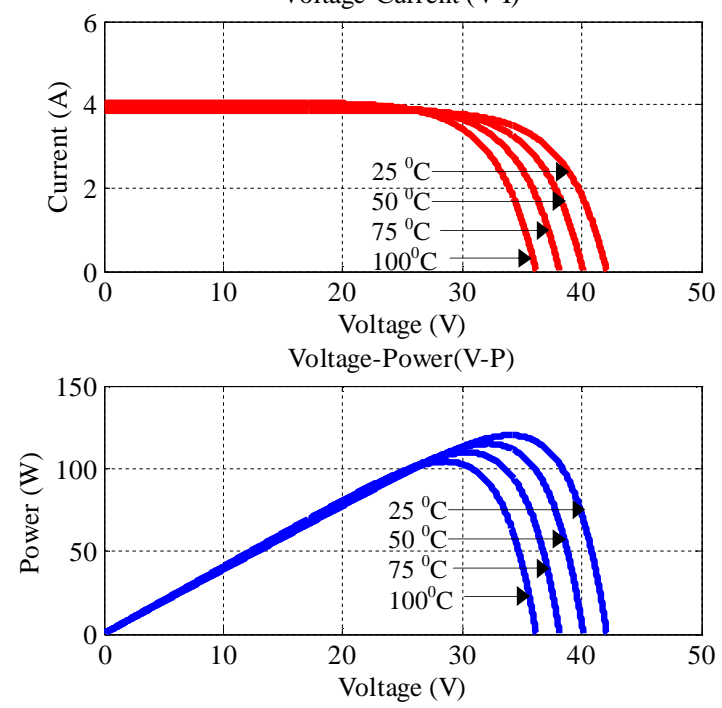

Fig. 2 V-I and V-P characteristics of the solar PV panel for different temperature values, $\mathrm{T}^{0} \mathrm{C}=(25 \text { to } 100)^{0} \mathrm{C}$ at the irradiation, $\mathrm{G}=1000 \mathrm{~W} / \mathrm{m}^{2}$

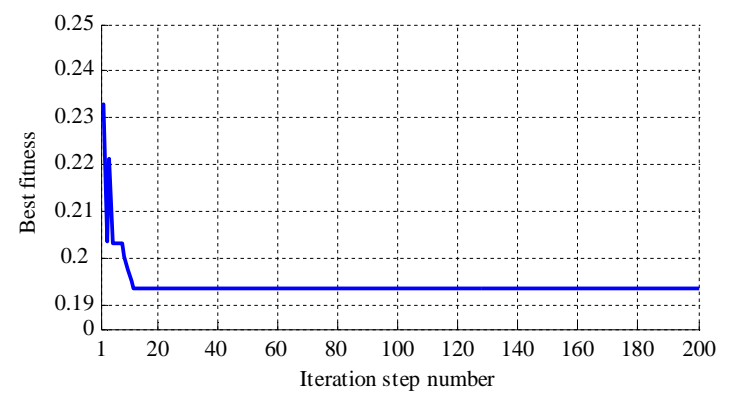

Fig. 3 Best fitness versus the iteration step number of the standard PSO algorithm 


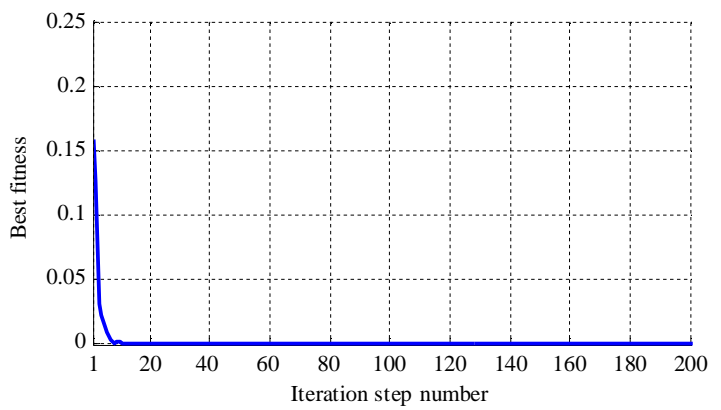

Fig. 4 Best fitness versus the iteration step number of the chaos PSO

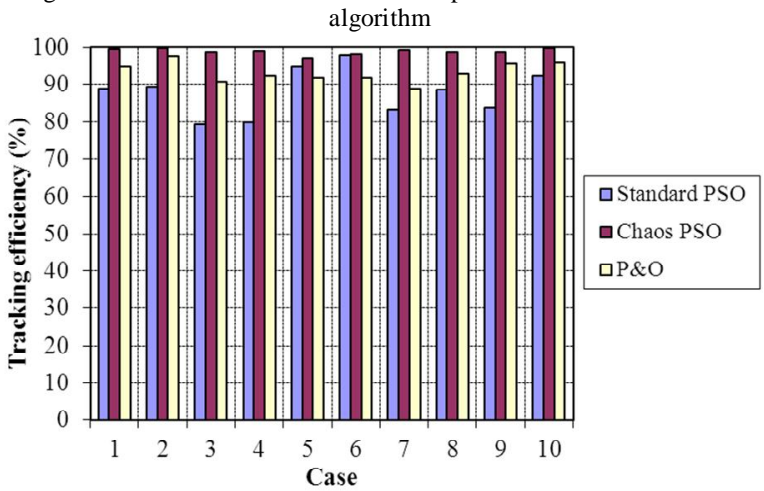

Fig. 5 Tracking efficiency of the MPPs of the solar PV panel using the standard PSO, chaos PSO and P\&O algorithms

\section{CONCLUSIONS}

In this paper, a novel application of the chaos PSO algorithm has been proposed for tracking MPPs of a solar PV panel. The chaos PSO algorithm is the combination of the standard PSO algorithm and the logistic map. The randomness-based parameters of the chaos PSO algorithm are initialized using the logistic map such as the initial random values of the estimated parameters, inertia weight in the velocity update equation and two independent random sequences. To achieve the improvement, the inertia weight in the chaos PSO algorithm was created with the best balance during the evolution process to produce the best convergence capability and search performance. Furthermore, the algorithm has also been improved because of the diversity in the PSO algorithm solution space using two independent chaotic random sequences. The simulation results of the tracking efficiencies obtained using the chaos PSO algorithm are compared with the results achieved using the standard PSO and $\mathrm{P} \& \mathrm{O}$ algorithms. The results confirm the validity of the proposed application. The tracking efficiencies produced by the proposal are always higher than $95 \%$ and higher than the efficiencies obtained using the standard PSO and P\&O algorithms of a solar PV panel.

\section{REFERENCES}

[1] G. M. Master, Renewable and efficient electric power systems, A John Wiley \& Sons, Inc., Publication, pp. 385-604, 2004.

[2] R. Faranda and S. Leva, "Energy comparison of MPPT techniques for PV systems", WSEAS Trans. Power Syst., vol. 3, iss. 6, pp. 446-455, 2008.
[3] R. Sridhar, S. Jeevananthan, N. T. Selvan and P. V. Sujith Chowdary, "Performance improvement of a photovoltaic array using MPPT P\&O technique", IEEE Int. Conf. Commun. Control and Comput. Technol., ICCCCT 2010, pp. 191-195, 2010.

[4] N. M. Razali and N. A. Rahim, "DSP-based maximum peak power tracker using $\mathrm{P} \& \mathrm{O}$ algorithm", IEEE First Conf. Clean Energy and Technol., CET 2011, pp. 34-39, 2011.

[5] B. Liu, S. Duan, F. Liu and P. Xu, "Analysis and improvement of maximum power point tracking algorithm based on incremental conductance method for photovoltaic array", 7th Int. Conf. Power Electron. and Drive Syst., PEDS 2007, pp. 637-641, 2007.

[6] W. Ping, D. Hui, D. Changyu and Q. Shengbiao, "An improved MPPT algorithm based on traditional incremental conductance method", 4th Int. Conf. Power Electron. Syst. and Applicat., PESA 2011, pp. 1-4, 2011.

[7] Y. Zhihao and W. Xiaobo, "Compensation loop design of a photovoltaic system based on constant voltage MPPT", Asia-Pacific Power and Energy Eng. Conf., APPEEC 2009, pp. 1-4, 2009.

[8] K. A. Aganah and A. W. Leedy, "A constant voltage maximum power point tracking method for solar powered systems", IEEE 43rd Southeastern Sym. Syst. Theory, SSST 2011, pp. 125-130, 2011.

[9] R. Ramaprabha, V. Gothandaraman, K. Kanimozhi, R. Divya and B. L. Mathur, "Maximum power point tracking using GA-optimized artificial neural network for solar PV system", 1st Int. Conf. Elect. Energy Syst., ICEES 2011, pp. 264-268, 2011.

[10] S. J. Kang, J. S. Ko, J. S. Choi, M. G. Jang, J. H. Mun, J. G. Lee and D. H. Chung, "A novel MPPT control of photovoltaic system using FLC algorithm", 11th Int. Conf. Control, Automat. and Syst., ICCAS 2011, pp. 434-439. 2011

[11] V. Padmanabhan, V. Beena and M. Jayaraju, "Fuzzy logic based maximum power point tracker for a photovoltaic system", Int. Conf. Power, Signals, Controls and Comput., EPSCICON 2012, pp. 1-6, 2012.

[12] Md. A. Azam, S. A. A. Nahid, M. M. Alam and B. A. Plabon, "Microcontroller based high precision PSO algorithm for maximum solar power tracking", Int. Conf. Inform., Electron. and Vision, ICIEV 2012, pp. 292-297, 2012.

[13] K. Ishaque, Z. Salam, M. Amjad and S. Mekhilef, "An improved particle swarm optimization (PSO)-based MPPT for PV with reduced steady-state oscillation", IEEE Trans. Power Electron., pp. 3627-3638, 2012.

[14] J. Kennedy and R. Eberhart, "Particle swarm optimization", Proc. IEEE Int. Conf. Neural Networks, vol. 4, pp. 1942-1948, 1995.

[15] F. V. D. Bergh, An analysis of particle swarm optimizers, Ph.D. dissertation, Dept. Comput. Sci., Pretoria Univ., Pretoria, South Africa, 2001.

[16] A. Ratnaweera, S. K. Halgamuge and H. C. Watson, "Self-organizing hierarchical particle swarm optimizer with time-varying acceleration coefficients", IEEE Trans. Evol. Comput., vol. 8, pp. 240-255, 2004.

[17] Y. Shi and R. Eberhart, "A modified particle swarm optimizer", Proc. IEEE Int. Conf. Evol. Computation, Piscataway, New Jersey, pp. 69-73, 1998.

[18] B. Alatas, E. Akin and A. B. Ozer, "Chaos embedded particle swarm optimization algorithms", J. Chaos, Solitons \& Fractals, vol. 40, issue 4, pp. 1715-1734, 2009.

[19] B. Liu, L. Wang, Y. H. Jin, F. Tang and D. X. Huang, "Improved particle swarm optimization combined with chaos", J. Chaos, Solitons \& Fractals, vol. 25, issue 5, pp. 1261-1271, 2005.

[20] H. J. Meng, P. Zheng, R. Y. Wu, X. J. Hao and Z. Xie, "A hybrid particle swarm algorithm with embedded chaotic search", Proc. 2004 IEEE Conf. Cybern. and Intelligent Syst., Singapore, pp. 367-371, 2004.

[21] Y. Feng, G. F. Teng, A. X. Wang and Y. M. Yao, "Chaotic inertia weight in particle swarm optimization", 2nd Int. Conf. Innovative Computing, Inform. and Control, ICICIC '07, pp. 475-478, 2007.

[22] Y. Feng, Y. M. Yao and A. X. Wang, "Comparing with chaotic inertia weights in particle swarm optimization", Proc. 6th Int. Conf. Mach. Learning and Cybern., Hong Kong, pp. 329-333, 2007.

[23] D. C. Huynh and M. W. Dunnigan, "Parameter estimation of an induction machine using advanced particle swarm optimization algorithms", IET J. Elect. Power Applicat., vol. 4, no. 9, pp. 748-760, 2010 . 
[24] D. Sera, R. Teodorescu and P. Rodriguez, "PV panel model based on datasheet values", IEEE Int. Sym. Ind. Electron., ISIE 2007, pp. 23922396, 2007.

TABLE III

OBTAINED $V_{\text {MPP }}, I_{M P P}$ AND $P_{\text {MPP }}$ OF THE SOLAR PV PANEL USING THE STANDARD PSO, CHAOS PSO AND P\&O ALGORITHMS

\begin{tabular}{|c|c|c|c|c|c|c|c|c|c|c|c|c|c|c|}
\hline \multirow{2}{*}{$\begin{array}{c}\text { Case } \\
\text { No. }\end{array}$} & \multirow{2}{*}{$\begin{array}{c}G \\
\left(\mathbf{W} / \mathbf{m}^{2}\right)\end{array}$} & \multirow{2}{*}{$\begin{array}{c}T \\
\left({ }^{0} \mathrm{C}\right)\end{array}$} & \multicolumn{3}{|c|}{ Theoretical values } & \multicolumn{3}{|c|}{ Standard PSO algorithm } & \multicolumn{3}{|c|}{ Chaos PSO algorithm } & \multicolumn{3}{|c|}{ P\&O algorithm } \\
\hline & & & $\begin{array}{c}V_{M P P} \\
(V)\end{array}$ & $\begin{array}{c}I_{M P P} \\
(A)\end{array}$ & $\begin{array}{c}P_{M P P} \\
(W)\end{array}$ & $\begin{array}{c}V_{M P P} \\
(V)\end{array}$ & $\begin{array}{c}I_{M P P} \\
(A)\end{array}$ & $\begin{array}{c}P_{M P P} \\
(W) \\
\end{array}$ & $\begin{array}{l}V_{M P P} \\
(V)\end{array}$ & $\begin{array}{c}I_{M P P} \\
(A)\end{array}$ & $\begin{array}{c}P_{M P P} \\
(W)\end{array}$ & $\begin{array}{c}V_{M P P} \\
(V)\end{array}$ & $\begin{array}{c}I_{M P P} \\
(A)\end{array}$ & $\begin{array}{c}P_{M P P} \\
(W)\end{array}$ \\
\hline 1 & 1000 & 25 & 33.70 & 3.56 & 120.00 & 30.42 & 3.50 & 106.47 & 33.68 & 3.55 & 119.56 & 32.77 & 3.47 & 113.71 \\
\hline 2 & 1000 & 30 & 33.72 & 3.57 & 120.38 & 30.53 & 3.52 & 107.47 & 33.73 & 3.56 & 120.08 & 32.90 & 3.57 & $\mathbf{1 1 7 . 4 5}$ \\
\hline 3 & 2000 & 25 & 35.31 & 7.06 & 249.29 & 30.50 & 6.48 & 197.64 & 35.00 & 7.03 & 246.05 & 32.87 & 6.88 & 226.15 \\
\hline 4 & 2000 & 30 & 35.77 & 7.11 & 254.32 & 30.91 & 6.57 & 203.08 & 35.62 & 7.07 & 251.83 & 33.80 & 6.94 & 234.57 \\
\hline 5 & 3000 & 30 & 35.84 & 10.66 & 382.05 & 31.45 & 11.51 & 361.99 & 36.01 & 10.29 & 371.47 & 34.04 & 10.30 & 350.61 \\
\hline 6 & 3000 & 40 & 36.72 & 10.74 & 394.37 & 32.19 & 12.01 & \begin{tabular}{|l|}
386.60 \\
\end{tabular} & 36.56 & 10.60 & 387.54 & 34.75 & 10.43 & 362.44 \\
\hline 7 & 4000 & 30 & 36.18 & 14.17 & 512.67 & 32.43 & 13.14 & 426.13 & 36.43 & 13.96 & 508.56 & 34.59 & 13.18 & 455.90 \\
\hline 8 & 4000 & 40 & 36.36 & 14.27 & 518.86 & 33.99 & 13.54 & 460.22 & 36.62 & 13.98 & 511.95 & 35.11 & 13.71 & 481.36 \\
\hline 9 & 5000 & 35 & 36.09 & 17.82 & 643.12 & 33.57 & 16.06 & 539.13 & 36.93 & 17.62 & 650.71 & 35.78 & 17.19 & 615.06 \\
\hline 10 & 5000 & 45 & 37.31 & 17.93 & 668.97 & 35.67 & 17.33 & 618.16 & 37.15 & 17.99 & 668.33 & 36.03 & 17.77 & 640.25 \\
\hline
\end{tabular}

